\title{
Existem diferenças nos parâmetros hematológicos e bioquímicos séricos entre fêmeas normais e portadoras do modelo experimental GRMD (Golden Retriever Muscular Dystrophy) ${ }^{1}$
}

\author{
Adriana C. Morini², Marina P. Brolio ${ }^{*}$, Adriana M.O.G. Millano², Laizi Z. \\ Braggio $^{2}$, Daniele S. Martins ${ }^{3}$, Felipe Perecin ${ }^{3}$, Carlos E. Ambrósio ${ }^{3}$ \\ e Maria A. Miglino 2
}

\begin{abstract}
Morini A.C., Brolio M.P., Millano A.M.O.G., Braggio L.Z, Martins D.S., Perecin F., Ambrósio C.E. \& Miglino M.A. 2011. [There are differences in hematological and biochemical parameters between carriers and not carriers of experimental model of GRMD (Golden Retriever Muscular Dystrophy)?] Existem diferenças nos parâmetros hematológicos e bioquímicos séricos entre fêmeas normais e portadoras do modelo experimental GRMD (Golden Retriever Muscular Dystrophy)? Pesquisa Veterinária Brasileira 31(1):9498. Setor de Anatomia dos Animais Domésticos e Silvestres, Departamento de Cirurgia, Faculdade de Medicina Veterinária e Zootecnia, Universidade de São Paulo, Av. Prof. Dr. Orlando Marques de Paiva 87, São Paulo, SP 05508-900, Brazil. E-mail: mpbrolio@usp.br

The purpose of this study was to evaluate whether there are alterations in hematological and biochemical patterns of female Golden Retriever dogs carrying the gene for progressive muscular dystrophy compared to not carriers dogs of the same breed, age and gender. We analyzed 33 animals, divided into two groups; one consisting of 13 not carriers dogs Golden Retrievers (GRNP) and the other composed of 14 dogs Golden Retrievers carrying the gene for muscular dystrophy (GRP). Animals of both groups underwent biochemical and hematological tests with the same frequency and at the same time interval. Although there is a statistically significant difference between groups for some hematological parameters evaluated, all results were in line with the benchmarks used. In the assessment of serum biochemical parameters in the determination of ALT GRS group was slightly above average, but without major clinical significance CK also showed high levels in GRP group, due to muscle degeneration and necrosis characteristic of the disease, the changes found in this analysis were already expected. The other parameters did not change.
\end{abstract}

INDEX TERMS: GRMD, serum biochemistry, hemogram, carriers, Golden Retriever, muscular dystrophy.

RESUMO.- A proposta deste estudo foi avaliar se existem alterações nos padrões hematológicos e bioquímicos de cadelas da raça Golden Retriever portadoras do gene da

\footnotetext{
${ }^{1}$ Recebido em 10 de janeiro de 2010.

Aceito para publicação em 26 de novembro de 2010.

2 Setor de Anatomia dos Animais Domésticos e Silvestres, Departamento de Cirurgia, Faculdade de Medicina Veterinária e Zootecnia (FMVZ), Universidade de São Paulo (USP), Av. Prof. Dr. Orlando Marques de Paiva 87, Cidade Universitária, São Paulo, SP 05508-900, Brasil. "Autor para correspondência: mpbrolio@usp.br

${ }^{3}$ Faculdade de Zootecnia e Engenharia de Alimentos (FZEA), USP, Av. Duque de Caxias Norte 225, Campus da USP, Pirassununga, SP 13635-900, Brasil.
}

distrofia muscular progressiva em comparação aos valores obtidos em cadelas não portadoras de mesma raça e idade. Foram analisados 33 animais, distribuídos em dois grupos, um composto por 19 cadelas Golden Retrievers não portadoras (GRNP) e outro composto por 14 cadelas Golden Retrievers portadoras do gene da distrofia muscular (GRP). Os dois grupos foram submetidos aos mesmos testes hematológicos e bioquímicos, com a mesma frequência e durante o mesmo intervalo de tempo. Apesar de existir diferença estatisticamente significativa entre os grupos para alguns parâmetros hematológicos avaliados, todos os resultados obtidos estavam de acordo com os va- 
lores de referência utilizados. Na avaliação dos parâmetros bioquímicos séricos a dosagem de ALT no grupo GRNP ficou levemente acima da média, porém sem grandes significados clínicos A CK também apresentou níveis elevados no grupo GRP, devido à degeneração e necrose muscular característicos da doença, as alterações encontradas nessa análise já eram esperadas. Os demais parâmetros não se alteraram.

TERMOS DE INDEXAÇÃO: GRMD, bioquímica sérica, hemograma, portadoras, Golden Retriever, distrofia muscular.

\section{INTRODUÇÃO}

Distrofia muscular de Duchenne (DMD) é uma doença muscular progressiva debilitante, causada por mutações recessivas ligadas ao cromossomo $\mathrm{X}$ no gene da proteína distrofina. (Chamberlain 1991, Chamberlain \& Rando 2006). As primeiras características clínicas incluem atraso no aprendizado para caminhar, incapacidade de correr corretamente e pseudo-hipertrofia dos músculos gastrocnêmios. Durante esta fase as fibras do músculo esquelético começam a degenerar e existe uma resposta inflamatória proeminente nesta musculatura. Isso é seguido por fraqueza muscular severa e contraturas articulares que tornam as crianças incapazes de andar por volta dos 9 a 13 anos. Conforme a doença progride, as fibras musculares são substituídas por tecido fibroso e células adiposas; essa substituição dos tecidos ocorre devido à ausência da distrofina estar acompanhada por uma perda do complexo distrofina-glicoproteína no sarcolema (Yugeta et al. 2006). DMD também está ocasionalmente associada a déficits cognitivos e alterações na musculatura lisa que afetam a digestão. Por fim, alterações cardíacas e insuficiência respiratória entre a segunda e terceira décadas de vida levam ao óbito.

Atualmente existem dois modelos animais mais utilizados para estudar a DMD; o modelo do camundongo $m d x$ e o modelo canino GRMD (Golden Retriever Muscular Dystrophy), sendo este um modelo promissor, pois além de apresentar os mesmos sinais clínicos já caracterizados em seres humanos (Kornegay et al. 1988, Valentine et al. 1990;, Valentine \& Cooper 1991, Nguyen et al. 2002, Shelton \& Engvall 2002, Collins \& Morgan 2003, Ambrósio et al. 2009), também carregam a mesma mutação vista em alguns pacientes DMD.

A GRMD manifesta-se inicialmente no período intrauterino, com alterações no desenvolvimento dos músculos linguais. Após o nascimento, observa-se extensa necrose dos músculos dos membros, tronco e pescoço dos animais doentes e aos seis meses, observa-se fibrose severa e contração das articulações (Collins \& Morgan 2003). Estudos tentam provar que as fêmeas portadoras, apesar de não desenvolverem a doença, podem apresentar alguns dos sintomas da mesma, ainda que mais sutis e não letais (Collins \& Morgan 2003).

Diante de estudos previamente realizados com o modelo animal canino levantou-se a questão de uma análise mais detalhada de parâmetros bioquímicos e hematológi- cos das cadelas portadoras do gene da GRMD; para tal também foi indagado se os valores de animais normais existentes na literatura poderiam ser utilizados como parâmetro comparativo de normalidade. Para responder a essas duas questões foram avaliados dados hematológicos e bioquímicos de fêmeas da raça Golden Retriever hígidas e portadoras do gene da GRMD de diferentes idades e os dados foram comparados aos disponíveis na literatura.

\section{MATERIAL E MÉTODOS}

O projeto proposto foi conduzido após avaliação da Comissão de Bioética da Faculdade de Medicina Veterinária e Zootecnia da Universidade de São Paulo (FMVZ-USP).

Foram utilizados 33 animais pertencentes ao Canil GRMDBrasil, localizado no Setor de Anatomia dos Animais Domésticos e Silvestres da FMVZ-USP. Os animais com idades variando entre um e sete anos, foram divididos em dois grupos: 14 cadelas Golden Retriever portadoras do gene da distrofia muscular (GRP) e 19 cadelas da raça Golden Retriever não portadoras da distrofia muscular (GRNP).

Amostras sanguíneas para a realização das provas bioquímicas e para a análise hematológica foram colhidas por punção da veia cefálica direita ou esquerda, utilizando-se sistema de colheita em tubos de vidro siliconizados de rolha de borracha (marca Vacuette ${ }^{\circledR}$ ). O tubo para os exames hematológicos continha anticoagulante $\left(\mathrm{EDTAK}_{3}\right)$, enquanto que os tubos de avaliação bioquímica eram sem adição de anticoagulante.

Após a coleta, as amostras de sangue foram centrifugadas a 1500 rotações por minuto (rpm) por cinco minutos. O soro e o plasma assim obtidos foram separados por aspiração com auxílio de pipetadores automáticos de volume fixo e variável, colocados em frascos resistentes ao congelamento, sendo o soro utilizado para a realização da bioquímica sérica: alaninaminotrasnferase (ALT), fosfatase alcalina (FA), uréia, creatinina, proteínas totais (PTs), albumina (Alb) e creatina cinase (CK).

As amostras sanguíneas com anticoagulante foram enviadas para o Laboratório de Análises Clínicas do Departamento de Clínica Médica da FMVZ- USP (LAC) para a realização da análise hematológica. No eritrograma foram avaliados os seguintes parâmetros: hemácias $(\mathrm{He})$, hemoglobina $(\mathrm{Hb})$, hematócrito $(\mathrm{Ht})$, volume corpuscular médio (VCM), hemoglobina corpuscular média (HCM) e concentração de hemoglobina corpuscular média ( $\mathrm{CHCM})$. A análise do leucograma incluiu leucócitos totais, neutrófilos segmentados, eosinófilos, linfócitos e monócitos. Plaquetas também foram avaliadas. Para contagem de hemácias, leucócitos e plaquetas foi utilizado apareIho de uso veterinário (Contador hematológico modelo $A B X$ Vet $\left.{ }^{\circledR}\right)$. O exame diferencial dos leucócitos e avaliação morfológica das hemácias e leucócitos foram realizados em esfregaços de sangue corados pelo método de Rosenfeld, observados em aumento de 500 vezes em microscópio (modelo Jenamed 2 Carl Zeiss).

As leituras foram realizadas em dosador semi-automático marca Labtest, modelo Labquest para provas bioquímicas, considerando-se a faixa visível para a dosagem de uréia, creatinina, ALT e fosfatase alcalina.

Os resultados obtidos foram analisados através da comparação das médias e dos desvios-padrões por análise de variância; e as médias obtidas entre os dois grupos foram comparadas entre si pelo teste Tukey. 


\section{RESULTADOS}

\section{Bioquímica sérica}

A avaliação e comparação dos parâmetros bioquímicos analisados entre os grupos GRP e GRNP indicaram diferenças estatisticamente significantes $(p<0,05)$; apenas para as variáveis $A L T$ (alanina aminotransferase) e $F A$ (fosfatase alcalina), os demais parâmetros apresentaram médias similares, todas dentro dos intervalos de referências utilizados (Quadro 1).

O parâmetro $A L T$ apresentou média de $37,15 \mathrm{UI} / \mathrm{L}$ para as fêmeas portadoras e $55,71 \mathrm{UI} / \mathrm{L}$ para os animais não portadores do gene.

As cadelas portadoras tiveram média de $34 \mathrm{UI} / \mathrm{L}$ para a FA (fosfatase alcalina), enquanto que as cadelas do outro grupo registraram média de $61,14 \mathrm{UI} / \mathrm{L}$ para a mesma enzima.

\section{Quadro 1. Médias e desvios padrões dos componentes bioquímicos avaliados em cadelas da raça Golden Retriever portadoras do gene da distrofia muscular progressiva (GRP) e não portadoras (GRNP)}

\begin{tabular}{lccc}
\hline Exame & GRP & GRNP & Referência $^{*}$ \\
\hline ALT (UI/L) & $37,15 \pm 13,25^{\mathrm{a}}$ & $55,71 \pm 28,04^{\mathrm{b}}$ & Até 50 \\
FA (Ul/L) & $34 \pm 15,5^{\mathrm{a}}$ & $61,14 \pm 35,9^{\mathrm{b}}$ & Até 70 \\
Ureia $(\mathrm{mg} / \mathrm{dL})$ & $39,05 \pm 15,23$ & $34 \pm 14,14$ & Até 40 \\
Creatinina $(\mathrm{mg} / \mathrm{dL})$ & $0,95 \pm 0,21$ & $0,95 \pm 0,48$ & Até $1,5-2,0$ \\
PTs $(\mathrm{g} / \mathrm{dL})$ & $6,04 \pm 0,96$ & $6,1 \pm 0,80$ & $5,5-8,5$ \\
Albumina $(\mathrm{g} / \mathrm{dL})$ & $3,04 \pm 1,04$ & $2,73 \pm 0,89$ & $2,7-4,6$ \\
CK (Ul/L) & $229,80 \pm 153,67$ & $160,33 \pm 50,19$ & $20-200$
\end{tabular}

Médias seguidas de letras diferentes na mesma linha diferem entre si $(p<0,05)$.

* Valores de Referência utilizados pelo Laboratório de Clínica Médica (LAC), Departamento de Clínica Médica/Hovet da FMVZ-USP. Para CK, valores de referência segundo Viana (2003).

Quadro 2. Médias e desvios padrões da análise de variância dos componentes hematológicos avaliados em cadelas da raça Golden Retriever portadoras do gene da distrofia muscular progressiva (GRP) e não portadoras (GRNP)

\begin{tabular}{lccc}
\hline Exame & GRP & GRNP & Referência $^{*}$ \\
\hline $\mathrm{He}\left(\mathrm{milh} / \mathrm{mm}^{3}\right)$ & $6,72 \pm 0,60$ & $6,52 \pm 0,79$ & $5,0-8,0$ \\
$\mathrm{Ht}(\%)$ & $44,70 \pm 3,60$ & $44,57 \pm 4,96$ & $37-54$ \\
$\mathrm{Hb}(\mathrm{g} \%)$ & $17,21 \pm 7,47$ & $15,21 \pm 1,99$ & $12-18$ \\
$\mathrm{VCM}(\mathrm{fl})$ & $69,90 \pm 2,51$ & $68,56 \pm 3,80$ & $60-77$ \\
$\mathrm{HCM}(\mathrm{pg})$ & $24,09 \pm 0,96$ & $23,35 \pm 1,3$ & $22-27$ \\
$\mathrm{CHCM}(\%)$ & $33,90 \pm 1,07$ & $34,50 \pm 1,18$ & $31-36$ \\
Leucócitos $^{\star *}$ & $12.050 \pm 1.238$ a & $9.800 \pm 1.940^{\mathrm{b}}$ & $6.000-15.000$ \\
Neutrófilos $^{* *}$ & $6.477 \pm 1.048$ & $5.960 \pm 2.566$ & $3.000-11.800$ \\
Eosinófilos $^{* *}$ & $268 \pm 213^{\mathrm{a}}$ & $573 \pm 275^{\mathrm{b}}$ & $0-750$ \\
Linfócitos $^{*}$ & $4.792 \pm 911^{\mathrm{a}}$ & $2.912 \pm 1.1933^{\mathrm{b}}$ & $1.500-5.000$ \\
totais & & & \\
Monócitos $^{* *}$ & $509 \pm 153 \mathrm{a}$ & $356 \pm 160^{\mathrm{b}}$ & $0-800$ \\
Plaquetas $^{* *}$ & $335.882 \pm 64.959$ & $274.429 \pm 88.395$ & $200.000-500.000$
\end{tabular}

Médias seguidas de letras diferentes na mesma linha diferem entre si $(p<0,05)$.

* Valores de Referência utilizados pelo Laboratório de Clínica Médica (LAC), Departamento de Clínica Médica / Hovet da FMVZ-USP.

${ }^{* *}$ Valores absolutos em $\mathrm{mm}^{3}$.

\section{Hemograma completo}

A análise comparativa dos parâmetros hematológicos avaliados entre os grupos GRP e GRNP apresentou similaridade na maioria dos itens examinados, porem . houve diferença significativa nos itens leucócitos, eosinófilos, linfócitos e monócitos; $(p<0,05)$, as médias e respectivos desvios padrões estão expressos no Quadro 2.

A média de leucócitos para as fêmeas GRPfoi de 12.050 $\mathrm{mil} / \mathrm{mm}^{3}$, enquanto que a média das cadelas GRNP ficou em $9.800 \mathrm{mil} / \mathrm{mm}^{3}$, enquanto que os eosinófilos apresentaram média de $268 \mathrm{mil} / \mathrm{mm}^{3}$ para os animais portadores e $573 \mathrm{mil} / \mathrm{mm}^{3}$ para o outro grupo.

As fêmeas GRNP apresentaram média de $4.792 \mathrm{mil} /$ $\mathrm{mm}^{3}$ para linfócitos típicos, enquanto que as portadoras tiveram média de $2.912 \mathrm{mil} / \mathrm{mm}^{3}$ para o mesmo item e no item monócitos apresentou média de $356 \mathrm{mil} / \mathrm{mm}^{3}$ para as fêmeas GRNP e $509 \mathrm{mil} / \mathrm{mm}^{3}$ para as cadelas portadoras.

\section{DISCUSSÃO}

A utilização de modelos não-humanos para a pesquisa da DMD é bastante discutível. As diferenças anatômicas, metabólicas e funcionais devem ser levadas em consideração e podem ter como consequência o sucesso ou não de determinados tratamentos, principalmente considerando uma importante diferença que é o fato de os humanos serem bípedes e os animais-modelo, quadrúpedes, o que influencia na utilização e importância de cada músculo nas espécies. Dunayer (1991) afirma que o ideal seria que as pesquisas para a DMD tivessem base em estudos in vitro e através da clínica humana, com resultados mais significativos do que os encontrados com os modelos animais. Contudo, o próprio autor afirma que a partir de estudos utilizando a GRMD, pode-se observar que esta doença e a DMD possuem muitas semelhanças com relação à etiologia e progressão.

Nguyen et al. (2002) discorda de Dunayer (1991), afirmando que a GRMD é geneticamente homóloga a DMD, o que justifica a utilização desses cães como modelos experimentais nos estudos da doença que acomete humanos. Considerando a semelhança genética e do desenvolvimento em ambas as doenças, consideramos plausível a utilização desses animais no auxílio na busca por tratamento para as crianças portadoras dessa doença.

A faixa etária dos animais utilizados no presente estudo foi escolhida em função dos animais disponíveis no Canil GRMD-Brasil na época do presente estudo. Também foi relevante o fato de que o LAC (2007), laboratório que analisou todas as amostras não possui valores de referências para diferentes faixas etárias, usando os mesmos intervalos, independente do animal ser filhote, adulto ou idoso. É importante também o fato de que as literaturas existentes que apresentam valores de referência divididos por faixa etária costumam dividir os animais em três grandes grupos: jovens até um ano de idade, entre um e oito anos de idade e acima de oito anos de idade (Comazzi et al. 2004).

Apesar de não existir diferença estatística entre os resultados mensurados para a enzima creatina cinase (CK) 
entre os dois grupos avaliados, apenas a média das fêmeas portadoras ficou um pouco acima do intervalo de referência utilizado (Viana 2003). Devido às alterações musculares causadas pela doença da qual são portadoras, a herança genética acarreta em alterações encontradas nas análises de $C K$, que já eram esperadas. Apesar da alteração nos níveis desse marcador de lesão muscular, é evidente que essas fêmeas não apresentam quaisquer dificuldades de locomoção ou deglutição, sinais típicos do desenvolvimento da doença em questão. A análise dessa enzima ao nascimento é um importante auxiliar no diagnóstico da GRMD, tanto nos machos afetados, como nas fêmeas portadoras e afetadas (Ambrósio et al. 2009). Vale ressaltar, que a $C K$ não é dosada comumente na avaliação de cães saudáveis, e são poucas as referências de literatura que apresentam intervalo de normalidade para esta enzima; o próprio LAC (2007) não estipula um valor de referência nos laudos emitidos.

A dosagem de $A L T$ apresentou diferença estatisticamente significante quando comparamos os grupos GRP e GRNP; além disso, a média obtida na avaliação do grupo das fêmeas não portadoras da GRMD esteve um pouco acima do intervalo considerado normal para o LAC (2007). Porém, o resultado seria considerado normal para Viana (2003) - 10 a $88 \mathrm{UI} / \mathrm{L}$; e também para Harper et al. (2003), Comazzi et al. (2004) e Franciscato et al (2007), que consideram normais os valores até $100 \mathrm{UI} / \mathrm{L}$. Deve-se lembrar que de acordo com Bush (2004); a $A L T$ é uma enzima essencialmente hepato-específica para cão e gato. Aumentos de sua atividade sérica em geral indicam dano nos hepatócitos com liberação da enzima para a circulação. A mensuração desta enzima é considerada o melhor teste para detecção de lesão hepática, porém não é um teste de função hepática. Assim, aumentos discretos na atividade sérica da $A L T$ provavelmente são de pouca importância, porque uma das funções do fígado é a desintoxicação, o que às vezes pode causar pequenas lesões aos hepatócitos.

Para Heins et al. (1995), valores elevados da concentração de ALT podem ser indicadores de distrofia muscular progressiva, o que não foi evidenciado nos animais em questão, uma vez que não foram avaliados animais distróficos. Nosso grupo concorda com o autor, no sentido de que grande elevação na concentração sérica da $A L T$ é uma característica de cães distróficos, porém não associada a causas primárias de dano e perda da função hepática, e sim pela sobrecarga do órgão em função da distrofia muscular.

Finalmente, levando em conta os diferentes intervalos de médias de normalidade para a enzima ALT entre as literaturas consultadas e considerando o estado clínico saudável de todos os animais no momento da realização das coletas, podemos considerar o valor obtido pelo grupo GRNP como dentro da normalidade, uma vez que pequenos aumentos da atividade sérica desta enzima não têm relevância.

Apesar da diferença estatisticamente significante entre os valores mensurados de $F A$ entre os dois grupos, a média do grupo GRNP foi quase o dobro da média do gru- po GRP; ambos os resultados estavam dentro dos valores normais de referência para LAC (2007) e também Viana (2003), Comazzi et al. (2004) e Thrall et al. (2006); entretanto para Mitruka \& Rawnsley (1977), os valores dos dois grupos estão acima do intervalo normal.

A dosagem da ureia plasmática esteve dentro do intervalo de normalidade do LAC (2007) em ambos os grupos avaliados, GRN e GRP. Apenas para Viana (2003) os resultados obtidos seriam considerados acima do normal; já para Mitruka \& Rawnsley (1977), Bush (2004), Comazzi et al. (2004) e Franciscato et al. (2007) os resultados estiveram normais para ambos os grupos. E importante ressaltar que todos os animais estavam em jejum hídrico e alimentar no momento das coletas de sangue, uma vez que aumentos temporários na concentração de ureia ocorrem após alimentação (Bush, 2004).

Os resultados obtidos para creatinina sérica foram iguais para os dois grupos avaliados e estavam normais de acordo com LAC (2007) e outras referências consultadas como Harper et al. (2003), Viana (2003), Bush (2004) e Thrall et al. (2006). Os resultados apresentaram-se bem próximos do intervalo considerado por Mitruka \& Rawnsley (1977), que considerou o intervalo de 1-2 mg/dl em seu experimentos com cães labradores.

As proteínas totais também apresentaram valores normais em ambos os grupos avaliados para LAC (2007); Harper et al. (2003), Viana (2003), Bush (2004), Comazzi et al. 2004), Thrall et al. 2006) e Franciscato et al. (2007); apenas para Weiner \& Bradley (1972) e Mitruka \& Rawnsley (1977) as médias encontradas estiveram um pouco abaixo do normal. Apesar dos valores obtidos estarem de acordo com os valores de referência utilizados, LAC (2007), é importante ressaltar que a ligeira diminuição na mensuração de $P T$ s é praticamente insignificante, podendo ser justificada pelo fato da albumina diminuir gradativamente com a idade, refletindo na diminuição das proteínas totais (Bush 2004) ou, por um período de dieta hipoprotéica ou ainda por ligeira hiperhidratação.

De acordo com LAC (2007) os valores de albumina estiveram normais para os dois grupos avaliados; e também para Viana (2003), Bush (2004), Comazzi et al. (2004), Thrall et al. (2006) e Franciscato et al. (2007), entretanto Weiner \& Bradley (1977) consideram intervalos maiores que as médias obtidas para ambos os grupos. Deve-se comentar que a média do grupo saudável esteve perto do limite inferior do intervalo de normalidade para o LAC (2007); isso pode ser justificado pelo mesmo motivo citado para as PTs; uma dieta hipoprotéica ou pelo fato da albumina diminuir gradativamente com a idade (Bush 2004).

A avaliação hematológica de ambos os grupos, GRP e GRNP, apresentou todos os resultados, tanto de eritrograma quanto leucograma, dentro dos intervalos de normalidade utilizados como referência para o LAC (2007). Esses valores também estavam de acordo com os valores preconizados por Lumsden et al. (1979), Navarro \& Pachaly (1994), Rebar et al. (2003), Bush (2004), Comazzi et al. (2004), Franciscato et al. (2007) e Cowell et al. (2009). 


\section{CONCLUSÕES}

As análises das fêmeas saudáveis da raça Golden Retriever (GRNP) e portadoras do gene da distrofia muscular (GRP), com idade entre um e sete anos, encontram-se dentro dos padrões bioquímicos e hematológicos considerados normais para a espécie canina, não apresentando diferenças significativas entre os dois grupos avaliados.

Os valores de CK encontrados nas cadelas GRP apresentaram-se acima dos limites superiores utilizados como referência para animais saudáveis, porém isto já era esperado em função do gene da distrofia muscular.

Mais exames devem ser necessários para que possamos identificar diferenças entre os parâmetros hematológicos e bioquímicos séricos em função da raça e idade dos cães portadores da distrofia muscular progressiva.

\section{REFERÊNCIAS}

Ambrósio C.E., Fadel L., Gaiad T.P., Martins D.S., Araújo K.P.C., Zucconi E., Brolio M.P., Giglio R.F., Morini A.C., Jazedje T., Froes T.R., Feitosa M.L.T., Valadares M.C., Beltrão-Braga P.C.B., Meirelles F.V. \& Miglino M.A. 2009. Identification of three distinguishable phenotypes in golden retriever muscular dystrophy. Genetics and Molecular Research 8(2):389-396.

Bush B.M. 2004. Interpretação de Resultados Laboratoriais para Clínicos de Pequenos Animais. Roca, São Paulo. 376p.

Chamberlain J.S. 1991. Duchene muscular dystrophy. Current Opinion in Genetics and Development 1:11-14.

Chamberlain J.C. \& Rando T.A. 2006. Duchene muscular dystrophy: Advances in therapeutics. Taylor and Francis, New York.

Collins C.A. \& Morgan J.E. 2003. Duchenne's muscular dystrophy: Animal models used to investigate pathogenesis and develop therapeutic strategies. Int. J. Exp. Pathol. 84(4):165-172.

Comazzi S., Pieralisi C. \& Bertazzolo W. 2004. Haematological and biochemical abnormalities in canine blood: Frequency and associations in 102 samples. J. Small Anim. Pract. 45:343-349.

Cowell R.L., Tyler R.D., Meinkoth J.H. \& DeNicola D.B. 2009. Diagnóstico Citológico e Hematologia de Cães e Gatos. 3르 ed. MedVet, São Paulo. 476p.

Dunayer E. 1991. Scientific problems with animal models of Duchenne muscular dystrophy. Perspec. Med. Res. 3:1-8.

Franciscato C., Lopes S.T.A., Teixeira M.M.G., Monteiro S.G., Wolkmer P., Garmatz B.C. \& Paim C.B. 2007. Cão naturalmente infectado por
Trypanosoma evansi em Santa Maria, RS, Brasil. Ciência Rural 37(1):288-291.

Harper E.J., Hackett R.M., Wilkinson J. \& Heaton P.R. 2003. Agerelated variations in hematologic and plasma biochemical test results in Beagles and Labrador Retrievers. J. Am. Vet. Assoc. 223(10):14361442.

Heins M., Heil W. \& Withold W. 1995. Storage of serum or whole blood samples? Effect of time and temperature on 22 serum analytes. European J. Clin. Chem. Clin. Biochem. 33(4):231-238.

Kornegay J.N., Tuler S.M., Miller D.M. \& Levesque D.C. 1988. Muscular dystrophy in a litter of golden retriever dogs. Muscle Nerve 11: 1056-1064

Lumsden J.H., Mullen K. \& McSherry B.J. 1979. Canine hematology and biochemistry reference values. Can. J. Comp. Med. 43(2):125131.

Mitruka B.M., Rawnsley H.M. \& Vadehra B.V. 1977. Clinical Biochemical and Hematological Reference Values in Normal Experimental Animals. Masson Publishing, New York, p.152-160.

Navarro C.E.K.G. \& Pachaly J.R. 1994. Manual de Hematologia Veterinária. Livraria Varela, São Paulo. 163p.

Nguyen F., Cherel Y., Guigand L., Goubault-Leroux I. \& Wyers M. 2002. Muscle lesions associated with dystrophin deficiency in neonatal golden retriever puppies. J. Comp. Pathol. 126(2/3):100-108.

Shelton G.D. \& Engvall E. 2002. Muscular dystrophies and other inherited myopathies. Vet. Clin. North Am., Small Anim. Pract. 32:103124.

Thrall M.A., Baker D.C., Campbell T., De Nicola D., Fettman M.J., Lassen E.D., Rebar A. \& Weiser G. 2006. Hematologia e Bioquímica Veterinária. Roca, São Paulo. 582p.

Valentine B.A., Cooper B.J., Cummings J.F. \& de Lahunta A. 1990. Canine X-linked muscular dystrophy: morphologic lesions. J. Neurol. Sci. 97:1-23.

Valentine B.A. \& Cooper B.J. 1991. Canine X-linked muscular dystrophy: selective involvement of muscles in neonatal dogs. Neuromuscular Disorders 1:31-38.

Viana F.A.B. 2003. Guia Terapêutico Veterinário. Gráfica e Editora CEM Ltda, Belo Horizonte. 324p.

Weiner D.J. \& Bradley R.E. 1972. The hemogram and certain serum protein fractions in normal Beagle dogs. Vet. Med. Small Anim. Clin. 67(4):393-398.

Yugeta N., Urasawa N., Fujii Y., Yoshimura M., Yuasa K., Wada M.R., Nakura M., Shimatsu M., Tomohiro M., Takahashi A., Machida N., Wakao Y., Nakamura A. \& Takeda S. 2006. Cardiac involvement in Beagle-based canine X-linked muscular dystrophy in Japan (CXMDJ): Electrocardiographic, echocardiographic, and morphologic studies. BMC Cardiovascular Disorders. 6:47. Doi 10.1186/1471-2261. 